\title{
Burunda Dev Yabancı Cisim: Rinolit
}

\author{
A Giant Foreign Body in Nose: Rhinolith
}

\section{Gökçe ŞİMŞEK ${ }^{1}$, Gül SOYLU ÖZLER ${ }^{2}$, Mikail İNAL ${ }^{3}$, Rahmi KILIÇ¹}

\author{
${ }^{I}$ Kırlkkale Üniversitesi Tip Fakültesi, KBB Anabilim Dall, KIRIKKALE \\ ${ }^{2}$ Mustafa Kemal Üniversitesi Tıp Fakültesi, KBB Anabilim Dall, HATAY \\ ${ }^{3}$ Kırıkkale Üniversitesi Tıp Fakültesi, Radyoloji Anabilim Dalı, KIRIKKALE
}

\begin{abstract}
ÖZET
Rinolit, tek taraflı ve kötü kokulu burun tıkanıklığına neden olan mineralleşmiş kitlelerdir. Tipik semptomlarına rağmen tanı ve tedavide gecikmelere sık rastlanmaktadır. Tanısal nazal endoskopi ve görüntüleme yöntemleri ile tanı konur. Kitle etkisiyle septal perforasyon, epistaksis, maksiller sinüs duvarında harabiyet ve oroantral fistül görülebilir. Tedavide endoskopik sinüs cerrahisi lokal ya da genel anestezi altında uygulanabilir. Bu yazıda epistaksis yakınmasıyla başvuran dev bir rinolit vakası literatür bilgileri eşliğinde sunuldu.
\end{abstract}

Anahtar Kelimeler: Burun, yabancı cisimler, ăğz kokusu, endoskopi

\section{GíRiş}

Rinolitler, nazal kavitede s1klıkla alt konka ve septum arasına yerleşmiş, özellikle kötü kokulu burun akıntısı, burun tıkanıklığı, epistaksis, kakozmi, baş ve yüzde ağrı, nazal regurjitasyon gibi yakınmalara neden olan mineralleşmiş kitlelerdir. Uzun zaman önce çeşitli yabancı cisimlerin burna girmesi sonucunda oluştuğuna inanılmaktadır (1). Genellikle hastalar böyle bir olayı hatırlamazlar ve güvenilir bir anamnez vermezler. Çocuk hastalarda etiyoloji daha çok eksojen olan düzensiz yüzeyli düğme, meyve çekirdekleri, bakliyat parçaları, balon lastiği, kağıt parçacıkları, bitki dal ve yaprakları gibi yabancı cisimlerdir (2). Nadir de olsa kan pıhtısı, kemik parçaları, kabuk gibi endojen yabancı cisimlerle de rinolit oluşabilmektedir. Çevre mukozanın ödemi ve rinolit etrafını saran granülasyon dokusunun varlığı, sadece anterior rinoskopiyi içeren fizik muayenede asıl tanının gözden kaçmasına ve

\begin{abstract}
Rhinolith, is mineralized mass causing unilateral and foulsmelling nasal congestion. Despite typical symptoms, delays in diagnosis and treatment are common. It is diagnosed with diagnostic nasal endoscopy and imaging methods. Septal perforation, epistaxis, destruction of the maxillary sinus wall and oroantral fistula may occur with the mass effect. In treatment, endoscopic sinus surgery may be performed under local or general anesthesia. In this article, a giant rhinolith case with the complaint of epistaxis was presented in the view of literature.
\end{abstract}

Keywords: Nose, foreign bodies, halitosis, endoscopy

hastaların kronik sinüzit, allerjik rinit, nazal polip gibi yanlış tanı almalarına neden olur (3). Rijit endoskopik muayene ve görüntüleme yöntemleriyle tanı kesinleşir. $\mathrm{Bu}$ yazıda epistaksis şikayetiyle başvuran dev rinolit vakası, güncel literatür bilgileri eşliğinde sunuldu.

\section{OLGU}

Birkaç gündür devam eden burun kanaması şikâyeti ile 68 yaşında erkek hasta kliniğimize başvurdu. Hastanın burun kanamasının birkaç kez, sızıntı şeklinde ve istirahatte iken olduğu öğrenildi. Koroner arter hastalığı, kronik obstruktif akciğer hastalığı ve hipertansiyon nedeniyle medikal tedavi alan hastanın kan basıncı normal sinırlardaydı. Anterior rinoskopiyi içeren kulak burun boğaz muayenesinde nazal septumun sağ tarafa deviasyonu dişında, Little bölgesi doğaldı ve herhangi bir vaskülarite artışı ya da hiperemiye rastlanmadi. Ancak hastanın sol nazal 
pasajında oldukça kötü kokulu pürülan sekresyon dikkati çekti. Sekresyon aspire edildikten sonra $0^{0}$ rijid endoskop ile yapılan muayenede, sol orta konkanın önaltından başlayan, sol alt konka ile septum arasını tamamen olduran ve endoskopun ileriye geçişini engelleyen, kahverengi-siyah renkte, dokunmakla ağrılı, hareketsiz, taş sertliğinde kitle lezyonu (Rinolit) izlendi. Sağ nazal kavitenin endoskopik muayenesinde ise kitlenin, septumu arka-altında 1-2 mm perfore ettiği izlendi. Bunun üzerine anamnez derinleştirildiğinde hastanın yirmi yıl demir-çelik fabrikasında çalıştığı, hiç sigara kullanmadığı ve beş yıldır da ağı kokusu nedeniyle birçok defa sağlık kuruluşlarına başvurduğu ancak bir sonuç alamadığı öğrenildi. Paranazal Sinüs Bilgisayarlı Tomografi (PNS-BT)'sinde sol nazal kavitede, alt ve orta konka arasından başlayıp koanaya kadar uzanan, septumda destrüksiyona neden olan, kemik yoğunluğunda (1510 HU) hiperdens, yumuşak doku bölümü de içeren, düzensiz sınırlı, merkezinde radyolusen nidusun bulunduğu yaklaşık 9x4x3cm'lik rinolit ile uyumlu kitle izlendi (Resim 1).

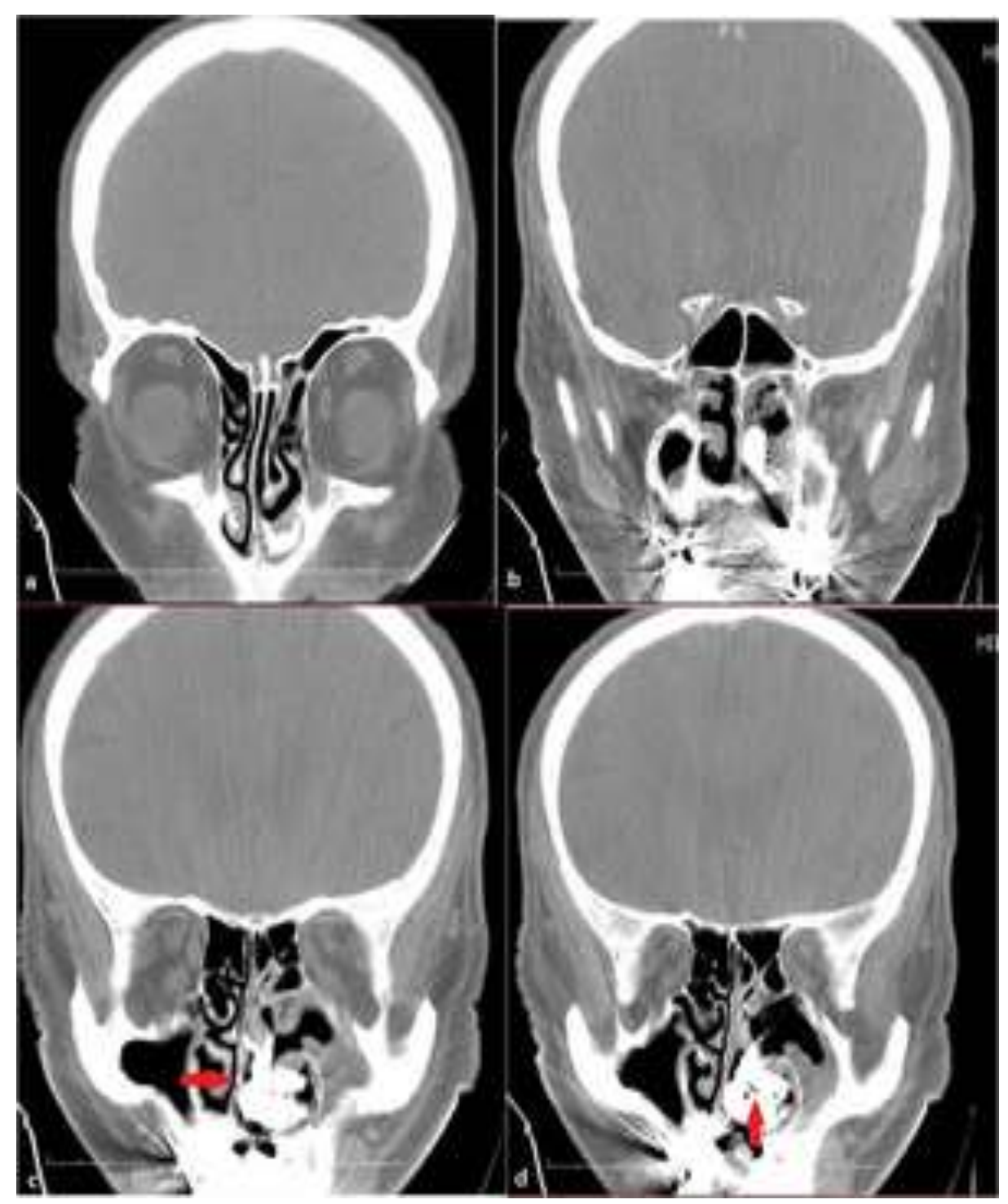

Resim 1: Koronal kesitleri içeren PNS-BT'de sol nazal kavitede yer kaplayan hiperdens kitle lezyonu (a) Kitlenin orta konka düzeyinden geçen kesit görüntüsü (b) Kitlenin posteriorda koanaya kadar uzandığı kesit görüntüsü (c) Düzensiz sınırlı kitlenin septumda yaptığı destrüksiyon (kırmızı ok) (d) Kitlenin santralinde radyolüsen nidus (kırmızı ok) 
Hastaya genel anestezi altında endoskopik yöntemle kitle eksizyonu planland. Rinolitin septum posteroinferiorunda perforasyona neden olduğu göz önünde bulundurularak kitlenin kaudal kısımları etmoid forseps yardımıyla kırılarak parça parça eksize edildi. Sol orta konka inferiorunda, inferior meatusu tama yakın dolduran, koanaya kadar uzanan, sert kıvaml, kötü kokulu, kahverengi- siyah renkli, $8 \times 4 \mathrm{~cm}$ boyutlarında kitle (Rinolit) tümüyle çıkarıldı (Resim2). Etraf nazal mukoza ödemli, hipertrofik ve frajil olarak izlendi. İnferior konka lateralinde, orta konka inferiorunda ve nazal tabandaki granulasyon dokuları kesici punch yardımıla alındı. Rinolitin üzerinde bulunduğu nazal taban mukozası kürete edildikten sonra gümüş nitrat ile koterize edildi. Septumdaki 1 mm'lik perforasyonun kenarları avive edilerek sekonder iyileşmeye bırakıldı (Resim-3). Kaviteye merosel tampon uygulaması sonrası ameliyata son verildi. Postoperatif dönemi sorunsuz geçiren hasta taburcu edildi. Septum perforasyonu daha sonra kapanan hastanın sifiliz ayırıcı tanısı için yapılan VDRL testi ve tüberküloz taraması negatif olarak bildirildi.

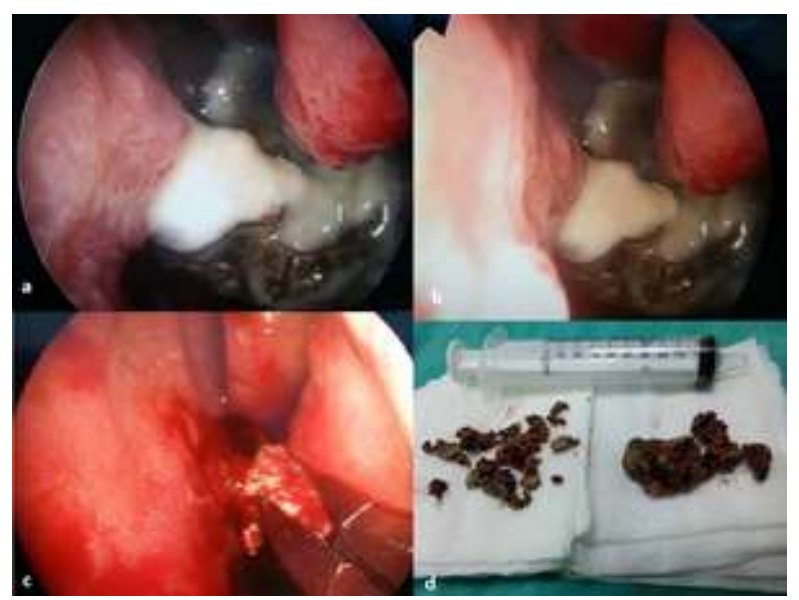

Resim 2: (a, b) İntraoperatif resimlerde pürülan akıntının eşlik ettiği, alt konka ve orta konka arasından başlayip, alt meatusu tam dolduran, kahverengi- siyah renkli kitle (c) Kitlenin kaudal kısımlarının etmoid forseps yardımıyla kırılarak parça parça çıkarılması (d) Hastanın sol nazal kavitesinden çıkarılan ve en büyüğü $8 \times 4 \mathrm{~cm}$ boyutlarında olan multiple kitleler.

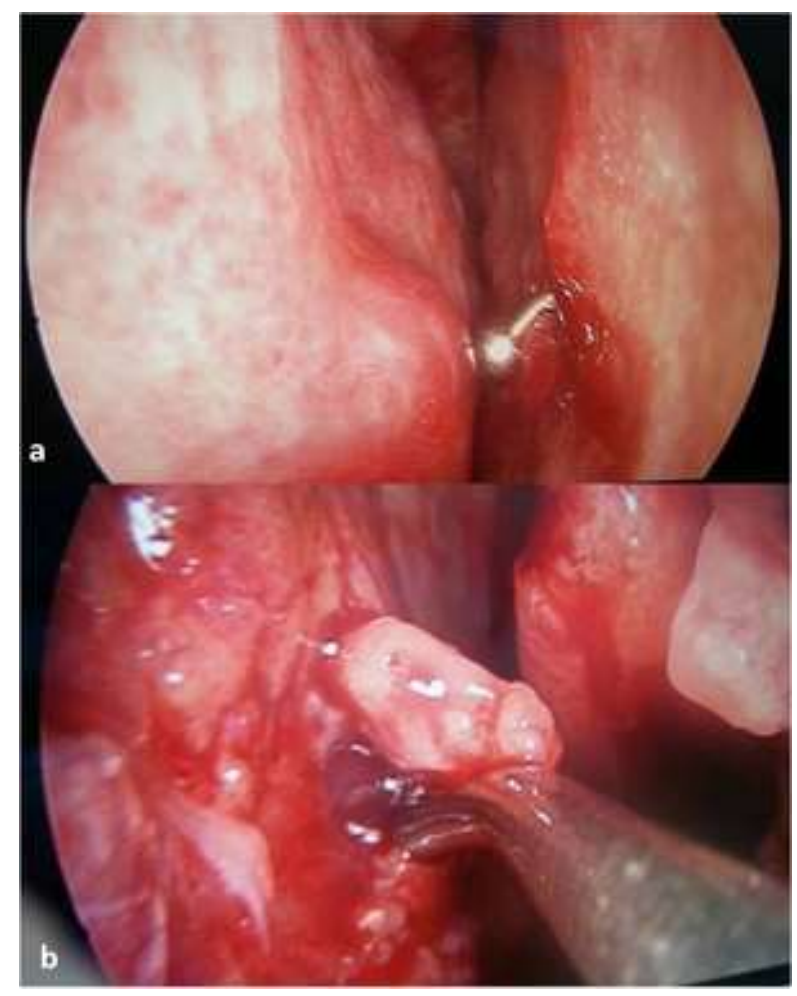

Resim 3: İntraoperatif görüntüde (a) Sağ taraf nazal pasaj endoskopik görüntüde kitlenin yarattı̆̆ $1 \mathrm{~mm}$ 'lik perforasyon (b) Sol nazal pasajda kitle çıkarıldıktan sonra septum perforasyonunun değerlendirilmesi

\section{TARTIŞMA}

Rinolit, kadınlarda erkeklere göre daha sık görülen, çocuklarda çok nadir olabilen, 30-40'lı yaşların hastalığıdır (1). Hastalarda en sık rastlanan yakınma kötü kokuyla ilgilidir. Kötü kokulu akıntı, halitozis, kakozmi, ağızda kötü tat bunlardan birkaçıdır (2). Daha sonra sırasıyla tek taraflı burun tıkanıklı̆̆ı, epistaksis, burun ve yüzde şişlik, ağrı, kabuklanma, epifora, anozmi, başağrısı, nazal regurjitasyon ve öksürük görülür (3). Fizik muayenede sık eşlik eden bulgu ve hastalıklar çevre mukozada ödem, hiperemi, granulasyon dokusu, karşı septumda deviasyon ile nazal polip, allerjik rinit ve kronik sinüzittir. Deviasyonun karşı tarafında oluşan türbülan akımın, sekresyonları kurutarak rinolit için ideal zemin oluşturduğu düşünülmektedir (4). Rinolit, yerleşimine ve yaygınlığına bağlı olarak çevre dokularda destrüksiyona neden olabilir. Bunların başında 
hastamizda da bulunan epistaksis ve septum perforasyonu gelir. Septum perforasyonu durumunda tüberküloz ve sifiliz ayırıcı tanısının yapılması gerekir. Diğer komplikasyonlar arasında oroantral fistül, maksiller sinüs duvarında destrüksiyon, kronik vestibülit yer alır (5). Etiyopatogenezde rinolitin endojen ya da eksojen bir yabancı cisim zemininde, çeşitli minerallerin çökmesiyle oluştuğuna inanılmaktadır. Rinolitin mineral incelemesinde kalsiyum stearat içeren sert bir oval çekirdek içerdiği ve bunu kalsiyum, fosfat, demir oksit, magnezyum, fosfor, sodyum gibi mineraler ile çevreleyen eşmerkezli ortalama 30 halkanın oluşturduğu bildirilmiştir. Elektron mikroskopik incelemesi ve $\mathrm{X}$ 1şını difraksiyon analizini içeren çalışmalara göre rinolitin içeriği ve halkaların sayısına bakarak, ne zaman oluşmaya başladığına dair bir yorum yapılamayacağı bildirilmiştir (6). Genel görüş, sunduğumuz olguda da olduğu gibi rinolitin en az 2030 yılda oluştuğu yönündedir. Doğan ve arkadaşları (7) rinolit tanısındaki gecikmenin 6 ay ile 8 yıl arasında değiştiğini bildirmişlerdir. Bader ve Hiliopoulos'un (8) sundukları olgu, literatürde şimdiye kadar en geç tanı konan ve en trajik hikâyeyi barındırmaktadır. Bu makalede, 10 yaşında iyatrojenik olarak burunda yabancı cisim unutulan, 37 ve 45 yaşlarında tipik semptomlarına rağmen muayenede tanısı atlanan, kötü koku nedeniyle sosyal olarak izole olup hiç evlenmeyen ve 71 yaşında raslantısal olarak rinolit tanıs1 koyulup tedavi edilen bayan hasta olgusu sunulmuştur. $\mathrm{Bu}$ olgudan anlaşılacağı üzere Rinolit, belirgin semptomlarına rağmen tanısı rahatlıkla atlanabilen bir durumdur. Sunduğumuz olguda da hasta ağız ve burundan gelen kötü kokudan duyduğu rahatsızlık üzerine defalarca hekime başvurmuş ancak fayda göremediğini belirtmiştir. Anterior rinoskopiye endoskopik muayenenin de eklenmesi, tanıdaki gecikmelerin önüne geçebilir. Günümüzde endoskopik yöntemle Rinolitin çıkarılması rinolitin primer tedavisi haline gelmiştir. Küçük kitlelerde lokal anestezi tercih edilir ancak mental retarde hasta, çocuk ve ileri yaş nüfusta ve kaviteye oranla büyük kitlelerin eksizyonunda genel anestezi hasta ve cerrah konforu için önerilir. Mink, Rinolitlerin ultrason litotiripsi yöntemiyle çıkarılabileceğini iddia etse de günümüzde pratik olmayan bir tedavi seçeneğidir. Çok büyük kitlelerde lateral rinotomi yaklaşımıyla kitle eksizyonu da yüksek cerrahi morbidite ve yüzde skar oluşumu gibi nedenlerden günümüzde terk edilmiş bir uygulamadır (9). Ayırıcı tanıda tek taraflı burun tıkanıklığı yapan kitlelerden akılda bulundurulması gerekenler kalsifiye polip, osteom, kondrom, hemanjiom, sifilitik veya tüberküloid kalsifikasyon, kalsifiye anjiofibrom, kondrosarkom ve osteosarkomdur. Yakın zamanda Özdemir ve arkadaşları (10), 63 yaşında bir hastada ilk defa rinolit ve yassı hücreli karsinom birlikteliğini rapor etmişlerdir. Bunun dışında rinolit olgularında paranazal sinüs tümörlerinin gelişimini bildiren yayın bulunmamaktadır.

Sonuç olarak rinolitler tek taraflı burun tıkanıklığg, kötü kokulu burun akıntısı, epistaksis gibi tipik yabancı cisim semptomlarıyla başvurur. Yıllar içerisine yayılan şikayetleri nedeniyle hastalardan yabancı cisim yönünde anamnez almak sıklıkla mümkün olmaz. Teknolojinin KBB pratiğinde gittikçe yaygınlaşması sonucu tanısal nazal endoskopiyi rinolojik muayenenin rutini haline getirmek, tanıda olabilecek gecikmelerin önüne geçebilir.

\section{KAYNAKLAR}

1. Yaşar H, Ozkul H, Verim A. Rhinolithiasis: a retrospective study and review of the literature. Ear Nose Throat J. 2009; 88(7): E24.

2. Yuca K, Caksen H, Etlik O, Bayram I, Sakin YF, Dülger H, Kiriş M. The importance of rigid nasal endoscopy in the diagnosis and treatment of rhinolithiasis. Auris Nasus Larynx. 2006; 33(1): 1922. 
3. Hsiao JC, Tai CF, Lee KW, Ho KY, Kou WR, Wang LF. Giant rhinolith: a case report. Kaohsiung J Med Sci. 2005; 21: 582-5.

4. Hadi U, Ghossaini S, Zaytoun G. Rhinolithiasis: a forgotten entity. Otolaryngol Head Neck Surg. 2002; 126(1): 48-51.

5. Ozdemir S, Akbas Y, Görgülü O, Selçuk T, Sayar C. Rhinolithiasis: review of 21 cases. Am J Rhinol Allergy. 2010; 24(6): 136-9.

6. Vink BW, van Hasselt P, Wormald R. A case of rhinolithiasis in botswana: a mineralogical, microscopic and chemical study. J Laryngol Otol. 2002; 116(12): 1036-40.

7. Dogan M, Dogan DO, Duger C, Polat S, Muderris S. Recurrent rhinolithiasis: a case report with review of the literature. West Indian Med J. 2012;61(7):760-3.

8. Brehmer D, Riemann R. The rhinolith-a possible differential diagnosis of a unilateral nasal obstruction. Case Rep Med. 2010; 2010: 845671.

9. Ayub-ur-Rehman, Muhammad MN, Moallam FA. Endoscopy in rhinolithiasis. J Coll Physicians Surg Pak. 2012; 22(9): 601-3.

10. Özdemir S, Görgülü O, Akbaş Y, Selçuk T, Sayar H, Tarkan Ö. An unusual co-presentation of rhinolithiasis and squamous cell carcinoma in the nasal cavity. J Craniomaxillofac Surg. 2012; 40(5): e137-9. 